\title{
A cross-sectional study to identify a set of risk factors for caprine herpesvirus 1 infection
}

\author{
S. Bertolini ${ }^{1 *} \mathbb{D}$, A. Rosamilia ${ }^{2}$, C. Caruso ${ }^{1}$, C. Maurella ${ }^{1}$, F. Ingravalle ${ }^{1}$ A. Quasso ${ }^{3}$, P. L. Acutis ${ }^{1}$, M. Pitti ${ }^{4}$, \\ L. Masoero ${ }^{1}$ and G. Ru ${ }^{1}$
}

\begin{abstract}
Background: Caprine herpesvirus 1 (CpHV-1) causes neonatal mortality and reproductive failure in goats. Despite its impact on herd reproductive performance, few studies have investigated the risk factors associated with CpHV-1 infection. The aim of this cross-sectional study was to identify potential herd- and host-level risk factors associated with CpHV-1 prevalence in a goat population with heterogeneous seropositivity for CpHV-1.

Results: Blood samples and individual data from 4542 goats were collected from 255 herds in Piedmont, Italy. Enzyme-linked immunosorbent assay (ELISA) and serum neutralization tests were carried out to detect antibodies against CpHV-1. A mixed-effects model was applied to identify any statistical association between CpHV-1 seropositivity and a set of putative host-level and herd-level risk factors. A total of 630 samples tested were found positive by ELISA (prevalence $=13.9 \%$; 95\% confidence interval (CI) 12.9-14.9). Of the 255 tested herds, 85 were classified as positive for the presence of at least one gB-positive animal (herd prevalence 33.3\%, 95\% Cl 27.5-39.2), with a within-herd prevalence between 0.7 and 100\% (Q1 = 17.6\%; median = 32.3\%; $\mathrm{Q} 3=50 \%)(\mathrm{Q}=$ quartiles). The prevalence ratios showed a statistical association with the following risk factors: breeds other than Saanen, older age, larger herd size, meat and extensive herds, and co-existence of CAEV-infected animals.
\end{abstract}

Conclusions: Results from this cross sectional study may help to elucidate the natural history of the infection and inform targeted strategies to control a disease with a potentially important impact on animal health and goat farming economy.

\section{Background}

Caprine herpesvirus 1 (CpHV-1), an alphaherpesvirus antigenically closely related to bovine herpesvirus type 1 (BoHV-1), causes systemic disease and neonatal mortality in 1- or 2-week old kids [1] and reproductive failure in adult goats. A serological testing is often inconclusive due to the antigenic similarity of ruminant alphaherpesviruses related to BoHV-1 [2]. The percentage of nucleotide sequence identity for $\mathrm{gB}$ gene among different herpesviruses is indeed greater than $78 \%$ [3].

Even though BoHV-1 virus does not play a major role in small ruminants, both the natural infection in goat by Tolari and coll., (1990) [4] and the susceptibility to

\footnotetext{
* Correspondence: silvia.bertolini@izsto.it

${ }^{1}$ Istituto Zooprofilattico Sperimentale del Piemonte, Liguria e Valle d'Aosta, Turin, Italy

Full list of author information is available at the end of the article
}

experimental infection by Six an coll. (2001) [5] have been reported. Therefore ad hoc diagnostic strategies have been developed to discriminate the two viruses based on combination of ELISA tests [6-8].

CpHV-1 infects animals through the genital [9-11] or the respiratory mucosa [11] and establishes latent infection in sacral or trigeminal ganglia depending on the route of infection and the following spread through the body [12]. Although CpHV-1 infection is usually subclinical in adult goats, it can be responsible for different disorders including respiratory diseases, fever and leukopenia [10], vulvovaginitis [13, 14], balanoposthitis [15], and neonatal mortality. Abortions can be induced by the infection of pregnant goats at 3-4 months of gestation [16-19]. Severe disease may occur in neonatal kids characterized by pyrexia, conjunctivitis, oculonasal discharge, dyspnea, ulcerative and 
necrotic lesions throughout the enteric tract and high morbidity and mortality [20-22].

First isolated in the 1970s in California [22] and Switzerland [21] from young kids with severe generalised infection, CpHV-1 has been found worldwide since then in symptomatic animals from New Zealand [23], Australia [14, 15], Norway [24], and Greece [25]. More recently, CpHV-1 was isolated during an outbreak of infectious pustular vulvovaginitis in goats [13]. In Italy, it was first isolated from latently infected goats in 1996 [26]. Serological surveys indicate a worldwide distribution of CpHV-1 infection $[14,21,22,27,28]$ and a widespread prevalence in Mediterranean countries where goats play an important economic role, with rates of more than $50 \%$ reported for Greece [25] and France [29], 36-43\% for southern Italy [30, 31 ], and $21 \%$ for Spain [32].

In general, it is not clear if clinical disease outbreaks may go unreported or if the infection is lowly pathogenic: where prevalence is high unexplained abortions and reproductive disorder, such as infertility and return to estrus, might be associated with undiagnosed infections [33-35] and might cause substantial economic loss, especially in countries with many goat herds [20, 27, 32, 34, 36]. Despite its impact on herd reproductive performance, few studies have investigated the risk factors associated with $\mathrm{CpHV}-1$ infection. To date, the use of natural mating, the herd size and the animal age have been reported as risk factor significantly positively associated with CpHV-1 prevalence $[28,33]$. The aim of this cross-sectional study was to identify potential herd- and host-level risk factors associated with $\mathrm{CpHV}$ - prevalence in a goat population with heterogeneous seropositivity for $\mathrm{CpHV}-1$.

\section{Results}

A total of 630 out of 4542 caprine blood samples tested positive in the BoHV-1 $\mathrm{gB}$ blocking ELISA (prevalence 13.9\%, 95\% confidence interval (CI) 12.914.9); $5.5 \%$ of the positives $(n=35)$ tested positive also in the BoHV-1 gE blocking ELISA. On subsequent testing in the serum neutralization assay, all the 630 samples were classified as positive for CpHV1 because of higher titers detected for this virus as compared with the titers for BoHV-1, by a factor of four dilutions. Of the 255 tested herds, 85 were classified as positive for the presence of at least one gB-positive animal (herd prevalence 33.3\%, 95\% CI 27.5-39.2), with a withinherd prevalence between 0.7 and 100\% (Q1 $=17.6 \%$; median $=32.3 \%$; $\mathrm{Q} 3=50 \%)(\mathrm{Q}=$ quartiles $)$.

Tables 1 and 2 show the results of the univariate analysis for host- and herd-risk factors, respectively. The prevalence ratios show a significant statistical association for all risk factors but sex. Both herd size and age showed a statistically linear dose-response trend with risk of infection. Table 3 presents the results of a multivariable mixed-effects Poisson regression model. Despite adjustment for confounding, all variables were still statistically associated with CpHV-1 infection except the presence of co-inhabitant cattle. This variable was therefore omitted in the last model.

The goodness of fit of this model was better than that of a fixed effects model, as shown by the Akaike information criterion (AIC) values of 1683.8 and 1811.4, respectively, showing a significant herd random effect. In the final model, a total of 2879 records was considered because of missing data related to the presence of caprine arthritis and encephalitis virus (CAEV) infection in the herds (689 records). The latter variable was omitted in a further model including 3568 records; however, as compared with the previous one, the effect of all risk factors was still statistically significant (in particular meat/mixed goats showed a prevalence ratio of 12.2, 95\% CI 1.9-78.9 and goats kept in extensive herds a prevalence ratio of $3.5,95 \% \mathrm{CI} 1.6-7.3$ ).

Table 1 Association between CpHV-1 seropositivity and potential host-level risk factors as estimated by univariate analysis for caprine herpesvirus-1 infection in Piedmont (Italy). $N=4542$ (PR= prevalence ratio)

\begin{tabular}{|c|c|c|c|c|c|c|}
\hline Risk factor & Exposure level & No. of tested animals & No. of positive animals & Prevalence (\%) & PR $(95 \% \mathrm{Cl})$ & $P$-values \\
\hline \multirow[t]{2}{*}{ Sex } & Female & 3762 & 581 & 15.4 & Referent & \\
\hline & Male & 244 & 35 & 14.3 & $0.93(0.66-1.3)$ & 0.671 \\
\hline \multirow[t]{4}{*}{ Breed } & Saanen & 629 & 9 & 1.4 & Referent & \\
\hline & Chamoisee & 784 & 45 & 5.7 & $4.0(2.0-8.2)$ & 0.000 \\
\hline & Alpine & 629 & 88 & 14.0 & $9.8(4.9-19.4)$ & 0.000 \\
\hline & All others & 1901 & 466 & 24.5 & $17.1(8.9-33.1)$ & 0.000 \\
\hline \multirow[t]{4}{*}{ Age $^{*}$} & 1. (2-16 months) & 914 & 47 & 5.1 & Referent & \\
\hline & 2. (17-31 months) & 913 & 80 & 8.8 & $1.7(1.2-2.4)$ & 0.004 \\
\hline & 3. (32-56 months) & 916 & 196 & 21.4 & $4.2(3.0-5.7)$ & 0.000 \\
\hline & 4 (> 56 months) & 917 & 265 & 28.9 & $5.6(4.1-7.7)$ & 0.000 \\
\hline
\end{tabular}

"extension of the Wilcoxon rank-sum test for the age variable $=15.5, P$ value $=0.000$ 
Table 2 Association between CpHV-1 seropositivity and potential herd-level risk factors as estimated by univariate analysis for caprine herpesvirus-1 infection in Piedmont (Italy). $N=4542$ ( $P R=$ prevalence ratio)

\begin{tabular}{|c|c|c|c|c|c|c|}
\hline Risk factor & Exposure level & No. tested animals & No. positive animals & Prevalence (\%) & PR $(95 \% \mathrm{Cl})$ & $P$-values \\
\hline \multirow[t]{2}{*}{ Presence of CAEV-infected goats } & No & 1610 & 57 & 3.5 & Referent & \\
\hline & Yes & 2132 & 428 & 20.1 & $5.7(4.3-7.5)$ & 0.000 \\
\hline \multirow[t]{2}{*}{ Breeding type } & Dairy & 859 & 8 & 0.93 & Referent & \\
\hline & Meat/mixed & 3581 & 613 & 17.1 & $18.4(9.2-36.9)$ & 0.000 \\
\hline \multirow[t]{2}{*}{ Management type } & Confined & 1753 & 104 & 5.9 & Referent & \\
\hline & Extensive & 2665 & 505 & 18.8 & $3.2(2.6-3.9)$ & 0.000 \\
\hline \multirow[t]{3}{*}{ Herd size (no. of animals) ${ }^{*}$} & 1 (<9 goats) & 506 & 50 & 9.9 & Referent & \\
\hline & 2 (9-21 goats) & 777 & 99 & 12.7 & $1.3(0.91-1.8)$ & 0.143 \\
\hline & 3 (>21 goats) & 3259 & 481 & 14.8 & $1.5(1.1-2.0)$ & 0.007 \\
\hline \multirow[t]{2}{*}{ Presence of co-inhabitant cattle } & No & 2221 & 158 & 7.1 & Referent & \\
\hline & Yes & 2321 & 472 & 20.3 & $2.9(2.4-3.4)$ & 0.000 \\
\hline
\end{tabular}

"extension of the Wilcoxon rank-sum test for the herd size variable $=3.11 ; P$ value $=0.002$

\section{Discussion}

This is the first study to seek associations between hostand herd-risk factors and CpHV-1 infection in Italian goats. The excess risk associated with several of these factors (breeds other than Saanen, older age, larger herd size, meat and extensive herds, and co-existence of CAEV-infected animals) was quantified by fitting a multivariable mixed-effects model that takes into account both the potential confounding effect of combined risk factors and the aggregation of animals in herds (herd random effect). While the risk factors examined here were similar to those known for bovine herpesvirus infections, CpHV-1 infection was also associated with two additional factors: meat/mixed breeding type and copresence of CAEV-infected animals in the goat herds.

The association of the infection with herd size and age has been reported also in a recent study [33]. The effect of aging on the risk may be explained by prolonged exposure to the virus over time, with age acting as a surrogate measure of cumulative exposure. This holds true also for life-long seropositivity in BHV-1 infection [37-41]. As suggested by previous studies in cattle, the

Table 3 The combined effect of risk factors according to the multivariable mixed-effects Poisson regression model for caprine herpesvirus-1 infection in Piedmont (Italy). $N=2879$ ( $\mathrm{PR}=$ prevalence ratio)

\begin{tabular}{|c|c|c|c|}
\hline Risk factor & Exposure level & PR $(95 \% \mathrm{Cl})$ & $P$-values \\
\hline \multirow[t]{4}{*}{ Breed } & Saanen & Referent & \\
\hline & Chamoisee & $2.9(1.0-8.7)$ & 0.053 \\
\hline & Alpine & $4.2(1.4-12.5)$ & 0.009 \\
\hline & All others & $4.4(1.6-12.1)$ & 0.005 \\
\hline \multirow[t]{4}{*}{ Age } & 1 (2-16 months) & Referent & \\
\hline & 2 (17-31 months) & $1.5(1.0-2.2)$ & 0.073 \\
\hline & 3 (32-56 months) & $2.9(1.9-4.4)$ & 0.000 \\
\hline & 4 (> 56 months) & $3.6(2.3-5.5)$ & 0.000 \\
\hline \multirow[t]{2}{*}{ Breeding type } & Dairy & Referent & \\
\hline & Meat/mixed & $11.5(1.2-113.8)$ & 0.037 \\
\hline \multirow[t]{2}{*}{ Management type } & Confined & 1.0 & \\
\hline & Extensive & $8.7(2.8-27.2)$ & 0.000 \\
\hline \multirow[t]{3}{*}{ Herd size (n. of animals) } & 1 (<9 goats) & Referent & \\
\hline & 2 (9-21 goats) & $1.4(0.7-3.0)$ & 0.323 \\
\hline & 3 (> 21 goats) & $2.7(1.4-5.3)$ & 0.003 \\
\hline \multirow[t]{2}{*}{ Presence of CAEV-infected goats } & No & Referent & \\
\hline & Yes & $5.4(2.3-12.8)$ & 0.000 \\
\hline
\end{tabular}


excess risk was also associated with herd size because larger herds are more likely to have cases since they have more animals at risk and more contacts with other herds through visits by animal handlers (e.g., veterinarians, farmers, inseminators) [37, 42-45]. The potential role of the number and frequency of new animal purchases could not be assessed because such data are, unfortunately, not recorded in the National Animal Registry system for sheep and goats. Finally, the smaller number of susceptible animals in small herds may limit the maintenance of infections over time [38].

The association with extensive running of a herd may, again, reflect a higher probability of transmission through contacts between susceptible and infected goats in situations where the farmer has less direct control over animal movement and behaviour. In contrast, the greater control typical of dairy goat herd management appears to confer dairy herds a protective effect, as seen even after having adjusted for breed. Generally, dairy farmers pay more attention to such health-related practices as selection of purchased animals and compliance with quarantine regulations and biosecurity standards. In meat herds the productive life of the animals is shorter and productivity is prioritized.

Moreover, the calculated risk for breed further confirms this observation. Most goats are reared for cheese production. Specifically, the Saanen breed is typically reared for the sale of fresh goat milk, which imposes stricter adherence to good biosecurity practices (pasture, reproduction, etc.) by dairy goat farms than farms where mixed breeds are reared. A greater or lesser susceptibility by breed cannot be excluded, however.

The strong association between the risk of herpesvirus and the presence of CAEV-infected animals highlights a potential for an epidemiological link between the two infections. Previous studies have found an association between bovine herpesvirus infection and other infectious diseases [38, 46] and showed that infectious diseases share common risk factors [45]. We cannot exclude that the presence of CAEV infection, which is frequently contracted in the first months of life without manifesting clinical symptoms $[47,48]$ may predispose infected animals to contracting other infectious diseases, and may also increase the probability of herpesvirus infection. Small ruminant lentivirus (SRLVs) does not infect lymphocytes, however, and immunodeficiency is not a significant feature in SRLV disease [49].

Finally, we think that the external validity of the results was not put at risk by the way the data has been collected: our cross-sectional dataset was not based merely on convenience sampling as the large majority of the sampled herds had been randomly recruited in the frame of the national brucellosis plan.

\section{Conclusions}

What the study does suggest is that the type of herd most at risk for CpHV-1 infection is a large one, extensively reared, of the meat or mixed breeding type, and with CAEV co-infection and in which the eldest animals are more likely to be infected. Because most of these risk factors are common to several infectious diseases, veterinary services should promote effective prevention strategies that increase adherence to biosecurity standards and good herd management practices. Better knowledge of the risk factors for CpHV1 infection is needed. Our results may help to elucidate the natural history of the infection and inform targeted strategies to control a disease with a potentially important impact on animal health and goat farming economy.

\section{Methods}

\section{Sample collection}

This cross-sectional study was conducted in Piedmont, Italy's second largest region in geographical area after Sicily, located in the northwest corner of the country where it borders with France and Switzerland. According to the latest National Animal Registry Office figures (as of 31/08/2013), the total regional goat population is 72,900 distributed across 7028 herds.

A total of 255 goat herds were sampled for this project from May 2008 to December 2010. These herds were comprised of 199 herds (78.0\%) sampled as part of the national plan for brucellosis prevention (81 of these herds were also on the CAE eradication and monitoring program); 14 herds (5.5\%) on the CAE programme but not part of the brucellosis programme; and 42 herds (16.5\%) sampled for non-specified reasons. On these farms, a total of 4542 animals were blood sampled; individual animal data (sex, age and breed) was also collected. The herd size ranged from 1 to 143 animals (Q1-3; median = 8; Q3 = 21).

As an age requirement for being part of this study, only animals over two months of age were recruited. Information at the herd-level (breeding type, management type, herd size, etc.) was downloaded from the official database of the National Animal Registry system which is provided by the veterinary officers of the Ministry of Health through routine annual censuses.

\section{Serological testing for $\mathrm{CpHV}-1$}

The same approach as that described by Thiry et al. (2008) was applied to detect antibodies to CpHV-1 using an ELISA that has a specificity of $100 \%$ and a sensitivity of $93.5 \%$.

\section{Elisa}

BoHV-1 is serologically related to CpHV-1 [2]. CpHV-1 antibodies are known to cross-react with BoHV-1 antigens. 
A BoHV-1 ELISA was used following the approach suggested by Thiry et al. (2008). The serum samples were tested to detect antibodies to the highly conserved $\mathrm{gB}$ of alphaherpesviruses by means of a commercially available ELISA (Herdchek Anti-IBR gB, Idexx, Germany) following the manufacturer's recommendations.

In order to rule out that the $\mathrm{CpV}-1$ positivity might be due to BoHV-1, the samples testing positive for $\mathrm{gB}$ antibodies were also tested for $\mathrm{gE}$ antibodies using a BoHV-1 blocking ELISA (Herdchek Anti-IBR gE, Idexx). This combination with BoHV-1 gE blocking ELISA allows to distinguish between CpHV-1 and BoHV-1. This was demonstrated by Thiry et al. (2008), where CpHV-1-infected goats are determined seropositive by BoHV-1 gB blocking ELISA and seronegative by BoHV-1 gE blocking ELISA. We used a gB blocking ELISA different from that Thiry et al. used, but the overall performance of the diagnostic techniques are similar.

Samples showing an inhibition of $<45 \%, 45 \%-55 \%$, and $>55 \%$ were classified as negative, doubtful, and positive, respectively. The serum samples classified as doubtful were subsequently analysed in a second round; those resulting doubtful on two tests were classified as CpHV-1 positive.

\section{Serum neutralization assay}

Since in some cases goats may still be gE positive although infected by CpHV-1 [34], serum samples found positive in both ELISAs $(n=35)$ were subsequently tested using a cross-serum neutralization assay to detect antibodies to both the goat and the bovine viruses. Serum neutralization assays were carried out according to the procedure described in the Manual of Diagnostic Test and Vaccines for Terrestrial Animals [50]. Briefly, serum samples were heated to $56{ }^{\circ} \mathrm{C}$ for $30 \mathrm{~min}$. Serial twofold dilutions of each serum sample were incubated at $37{ }^{\circ} \mathrm{C}$ for $2 \mathrm{~h}$ in the presence of 100 TCID50/cell of CpHV-1 Ba-1 strain [26] or 24 $\mathrm{h}$ in the presence of 100 TCID50/cell of BoHV-1 [50]. Each virus-serum dilution was then dispensed into 96 wells on microtiter plates containing Madin-Darby bovine kidney (MDBK) cells grown and incubated at $37{ }^{\circ} \mathrm{C}$. The plates were read 3 days later. The titer of each serum is expressed as the highest dilution that neutralized the virus.

\section{Statistical analysis}

Goat-level prevalence of $\mathrm{CpHV}-1$ and within-herd prevalence were computed as the percentage of goat cases and relative $95 \% \mathrm{CI}$. We carried out a preliminary univariate analysis to identify any statistical association between CpHV-1 seropositivity (dependent variable) and potential risk factors: the respective prevalence in the exposed and the non-exposed animals was used to obtain prevalence ratios and relative 95\% CI. When the 95\% CI of the prevalence ratios did not include the null value $(\mathrm{PR}=1)$, the findings were considered statistically significant.

Animal characteristics (sex, breed, and age) were used as host-level factors; herd-level factors were breeding type (dairy/meat/mixed), management type (extensive/ confined), herd size, presence of CAEV-infected goats and of co-inhabitant cattle. As mentioned above, the herd-level data were obtained through a record linkage technique based on official herd identifiers to link our database with the National Animal Registry system. The databases and the data processes for statistical analysis were created with Stata Software 11.1 (Stata Corp, College Station, TX). Age and herd size were categorized into classes based on quartiles (first and second quartiles were conflated in a single category for herd size). The prevalence ratios were then estimated separately for each stratum using the lowest category as the reference. An extension of the Wilcoxon rank-sum test was used to evaluate trends in the prevalence ratios across strata of increasing age and herd size. For the "breed" variable, the less numerous breeds were grouped into a single class. Taking into account the cross-sectional study design and the clustering due to herds, we fit a mixedeffects Poisson regression model $(N=2879)$ with robust variance using the xtpoisson command to obtain adjusted prevalence ratios [51]. All variables that were statistically associated with CpHV-1 infection at the univariate analysis were then entered as independent variables, including "herd" as a random-effect variable. Finally, the AIC was applied to compare the mixed versus the fixed-effect models [52]. Due to the large proportion of missing values affecting the variable "presence of CAEV-infected goats", a model omitting the variable was also fitted $(N=3568)$ in order to increase the number of total observations included in the analysis.

As all samples collected during the mentioned time window were considered for analysis, a prior calculation of the statistical power when comparing two independent proportions (i.e. in animals from the referent group and exposure level group) was carried out before the statistical analysis using WinPepi (version 11.65, http:// www.brixtonhealth.com/pepi4windows.html): given a 95\% significance level, thanks to the large available sample sizes (i.e. 2879 or 3568 goats respectively in the two final models), a $80 \%$ power could easily obtained to detect prevalence ratios between 1.5 and 2 .

\section{Abbreviations}

AIC: Akaike information criterion; BoHV-1: Bovine herpesvirus type 1; CAE: Caprine arthritis encephalitis; CAEV: Caprine arthritis and encephalitis virus; Cl: Confidence interval; CpHV-1: Caprine herpesvirus 1; gB: Glycoprotein B; gE: Glycoprotein E; PR: Prevalence ratio; Q: Quartiles; SRLVs: Small ruminant lentivirus

Acknowledgements

Not applicable 


\section{Funding}

This research was supported by the Ministry of Health.

\section{Availability of data and materials}

The datasets used and analysed during the current study are available from the corresponding author on reasonable request.

\section{Authors' contributions}

SB, GR, CM: conceived the study, participated in its design and data analysis, and drafted the manuscript. AR: participated in the study design, carried out the laboratory analysis and drafted the manuscript. CC, PLA, MP, LM: participated in the study design, carried out the laboratory analysis and reviewed the paper. Fl assisted in the data analysis and reviewed the paper. AQ collected the samples and reviewed the paper. All authors read and approved the final manuscript.

\section{Ethics approval and consent to participate}

Blood samples were collected by the veterinary officers of the Regional Veterinary Services in the frame of approved national and regional animal disease plans. The veterinary officers daily operate on animal farms complying with the animal welfare procedures. When the study started (2008), in Italy there wasn't any requirement for a research being approved by an institutional ethics committee or Institutional Animal Care and Use Committee. The goat owners were informed and they were consenting about the inclusion of their animal blood samples for research purposes.

\section{Consent for publication}

Not applicable

\section{Competing interests}

None of the authors of this paper has a financial or personal relationship with other people or organizations that could inappropriately influence or bias the content of the paper.

\section{Publisher's Note}

Springer Nature remains neutral with regard to jurisdictional claims in published maps and institutional affiliations.

\section{Author details}

'Istituto Zooprofilattico Sperimentale del Piemonte, Liguria e Valle d'Aosta, Turin, Italy. ${ }^{2}$ Istituto Zooprofilattico Sperimentale dell'Abruzzo e del Molise G. Caporale, Teramo, Italy. ${ }^{3}$ Local Health Unit AT, Asti, Italy. ${ }^{4}$ Local Health Unit TO4, Turin, Italy.

\section{Received: 23 October 2015 Accepted: 28 February 2018}

\section{Published online: 14 March 2018}

\section{References}

1. Van der Lugt JJ, Randles JL. Systemic herpesvirus infection in neonatal goats. J S Afr Vet Assoc. 1993;64:169-71.

2. Thiry J, Keuser V, Muylkens B, Meurens F, Gogev S, Vanderplasschen A, Thiry E. Ruminant alphaherpesviruses related to bovine herpesvirus 1. Vet Res. 2006;37:169-90.

3. Griffin AM. The nucleotide sequence of the glycoprotein gB gene of infectious laryngotracheitis virus: analysis and evolutionary relationship to the homologous gene from other herpesviruses. J Gen Virol. 1991; 72(Pt 2):393-8.

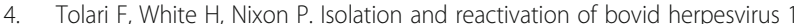
in goats. Microbiologica. 1990;13:67-71.

5. Six A, Banks M, Engels M, Ros Bascuñana C, Ackermann M. Latency and reactivation of bovine herpesvirus 1 (BHV-1) in goats and of caprine herpesvirus 1 (CapHV-1) in calves. Arch Virol. 2001;146:1325-35.

6. Nogarol C, Bertolotti L, De Carlo E, Masoero L, Caruso C, Profiti M, Martucciello A, Galiero G, Cordioli P, Lelli D, Nardelli S, Ingravalle F, Rosati S. Expression and antigenic characterization of bubaline herpesvirus 1(BuHV1) glycoprotein $\mathrm{E}$ and its potential application in theepidemiology and control of alphaherpesvirus infections in Mediterranean water buffalo. J Virol Methods. 2014;207:16-21

7. Bertolotti L, Rosamilia A, Profiti M, Brocchi E, Masoero L, Franceschi V, Tempesta M, Donofrio G, Rosati S. Characterization of caprine herpesvirus 1
(CpHV1) glycoprotein E and glycoprotein I ectodomains expressed in mammalian cells. Vet Microbiol. 2013;164:222-8.

8. Thiry J, Widén F, Grégoire F, Linden A, Belák S, Thiry E. Isolation and characterisation of a ruminant alphaherpesvirus closely related to bovine herpesvirus 1 in a free-ranging red deer. BMC Vet Res. 2007:28:3-26

9. Tempesta M, Buonavoglia D, Sagazio P, Pratelli A, Buonavoglia C. Natura reactivation of caprine herpesvirus 1 in latently infected goats. Vet Rec. 1998;143:200. https://doi.org/10.1136/vr.143.7.200.

10. Tempesta M, Pratelli A, Corrente M, Buonavoglia C. A preliminary study on the pathogenicity of a strain of caprine Herpesvirus-1. Comp Immuno Microbiol Infect Dis. 1999;22:137-43. https://doi.org/10.1016/S01479571(98)00029-0.

11. Tempesta M, Greco G, Camero M, Bozzo G, Guarda F, Buonavoglia C. Virological and histological findings in goats infected by caprine herpesvirus 1. New Microbiol. 2002;25:281-4.

12. Tempesta M, Pratelli A, Greco G, Martella V, Buonavoglia C. Detection of caprine herpesvirus 1 in sacral ganglia of latently infected goats by PCR. J Clin Microbiol. 1999:37:1598-9.

13. Piper KL, Fitzgerald CJ, Ficorilli N, Studdert MJ. Isolation of caprine herpesvirus 1 from a major outbreak of infectious pustular vulvovaginitis in goats. Aust Vet J. 2008;86:136-8.

14. Grewal AS, Wells R. Vulvovaginitis of goats due to a herpesvirus. Aust Vet J. 1986:63:79-82.

15. Tarigan S, Webb RF, Kirkland D. Caprine herpesvirus from balanoposthitis. Aust Vet J. 1987:64:321

16. Papanastasopoulou M, Koptopoulos G, Lekkas S, Papadopoulos O, Ludwig $\mathrm{H}$. An experimental study on the pathogenicity of the caprine herpesvirus type 1 (CHV-1) comp. Immunol Microbiol Infect Dis. 1991;14:47-53. https:// doi.org/10.1016/0147-9571(91)90040-K.

17. Williams NM, Vickers ML, Tramontin RR, Petrites-Murphy MB, Allen GP. Multiple abortions associated with caprine herpesvirus infection in a goat herd. J Am Vet Med Assoc. 1997;211:89-91.

18. Tempesta M, Camero M, Sciorsci RL, Greco G, Minoia R, Martella V, Pratelli A, Buonavoglia C. Experimental infection of goats at different stages of pregnancy with caprine herpesvirus 1. Comp Immunol Microbiol Infect Dis. 2004;27:25-32. https://doi.org/10.1016/S0147-9571(03)00012-2.

19. McCoy MH, Montgomery DL, Bratanich AC, Cavender J, Scharko PB, Vickers ML. Serologic and reproductive findings after a Herpesvirus-1 abortion storm in goats. J Am Vet Med Assoc. 2007;231:1236-9. https://doi.org/10. 2460/javma.231.8.1236.

20. Roperto F, Pratelli A, Guarino G, Ambrosio V, Tempesta M, Galati P, lovane G, Buonavoglia C. Natural caprine herpesvirus 1 (CpHV-1) infection in kids. J Comp Pathol. 2000;122:298-302.

21. Mettler F, Engels M, Wild P, Bivetti A. Herpesvirus infection in kids in Switzerland. Schweiz Arch Tierheilkund. 1979;121:655-62.

22. Saito JK, Gribble DH, Berrios PE, Knight HD, McKercher DG. A new herpesvirus isolate from goats: preliminary report. Am J Vet Res. 1974;35:847-8.

23. Horner GW, Hunter R, Day AM. An outbreak of vulvovaginitis in goats caused by a caprine herpesvirus. N Z Vet J. 1982;30:150-2.

24. Kao M, Leiskau T, Koptopoulos G, Papadopoulos O, Horner OW, Hyllseth B, Fadel M, Gedi AH, Straub OC, Ludwig H. Goat herpesvirus infections: a survey on specific antibodies in different countries survey on specific antibodies. In: Thiry E, Sapliki J, Pastoret PP, editors. Immunity to herpesvirus infections of domestic animals. Commission of the European Communities: 1985. p. 93-7.

25. Koptopoulos G, Papanastasopoulou M, Papadopoulos O, Ludwig H. The epizootiology of caprine herpesvirus (BHV-6) infections in goat populations in Greece. Comp Immunol Microbiol Infect Dis. 1988;11: 199-205.

26. Buonavoglia C, Tempesta M, Cavalli A, Voigt V, Buonavoglia D, Conserva A, Corrente M. Reactivation of caprine herpesvirus 1 in latently infected goats. Comp Immunol Microbiol Infect Dis. 1996;19:275-81

27. Chénier S, Montpetit $C$, Hélie P. Caprine herpesvirus-1 abortion storm in a goat herd in Quebec. Can Vet J. 2004;45:241-3.

28. Silva ML, Pituco EM, Nogueira AH, Martins MS, Lima MS, de Azevedo SS Serological evidence and risk factors associated with caprine herpesvirus 1 in dairy goat flocks in a semiarid region of northeastern Brazil. J Vet Diagn Investig. 2013;25:125-8.

29. Thiry J, Keuser V Schynts F, Chartier C, Tempesta M, Espejo-Serrano J, Saegerman C, Thiry E. Evaluation de la prévalence sérologique de l'infection 
à herpésvirus caprin 1 dans le sud-ouest de l'Europe. Epidèmiol et Santé Anim. 2006;49:55-8.

30. Guercio A, Greco A, lannizzotto G, Di Marco V, Todaro M. Valutazione della diffusione di anticorpi anti Herpes Virus della capra in allevamenti caprini della Sicilia. Atti della Società Italiana di Patologia Allevamento Ovini e Caprini. 1998;12:138-42.

31. Tempesta M, Cavalli A, Voigt V, Buonavoglia D. Presenza di anticorpi per Caprine herpesvirus 1 (CapHV-1) in allevamenti caprini dell'ttalia meridionale. Atti della Società Italiana di Patologia e Allevamento Ovini e Caprini. 1994;11:121-2.

32. Keuser V, Espejo-Serrano J, Schynts F, Georgin JP, Thiry E. Isolation of caprine herpesvirus type 1 in Spain. Vet Rec. 2004;154:395-9.

33. Suavet $F$, Champion JL, Bartolini L, Bernou M, Alzieu JP, Brugidou R, Darnatigues S, Reynaud G, Perrin C, Adam G, Thiéry R, Duquesne V. First description of infection of caprine herpesvirus $1(\mathrm{CpHV}-1)$ in goats in mainland France. Pathogens. 2016;5(1):17.

34. Thiry J, Saegerman C, Chartier C, Mercier P, Keuser V, Thiry E. Serological evidence of caprine herpesvirus 1 infection in Mediterranean France. Vet Microbiol. 2008;128:261-8.

35. Keuser V, Gogev S, Schynts F, Thiry E. Demonstration of generalized infection with caprine herpesvirus 1 diagnosed in an aborted caprine fetus by PCR. Vet Res Commun. 2002;26:221-6.

36. Marinaro M, Rezza G, Del Giudice G, Colao V, Tarsitano E, Camero M, Losurdo M, Buonavoglia C, Tempesta M. A caprine herpesvirus 1 vaccine adjuvanted with MF59 $9^{T M}$ protects against vaginal infection and interferes with the establishment of latency in goats. PLoS One. 2012;7:4.

37. Boelaert F, Speybroeck N, de Kruif A, Aerts M, Burzykowski T, Molenberghs $\mathrm{G}$, Berkvens DL. Risk factors for bovine herpesvirus-1 seropositivity. Prev Vet Med. 2005:69:285-95.

38. Carbonero A, Saa LR, Jara DV, García-Bocanegra I, Arenas A, Borge C, Perea A. Seroprevalence and risk factors associated to bovine herpesvirus 1 (BHV -1) infection in non-vaccinated dairy and dual purpose cattle herds in Ecuador. Prev Vet Med. 2011;100:84-8.

39. Kadohira M, McDermott JJ, Shoukri MM, Thorburn MA. Assessing infections at multiple levels of aggregation. Prev Vet Med. 1997;29:161-77.

40. Van Wuijckhuise LW, Bosch J, Franken P, Hage H, Verhoeff J, Zimmer $\mathrm{G}$. The prevalence of infectious bovine rhinotracheitis (IBR) in the Netherlands, vol. 7. The Netherlands: Proceedings of the Dutch Society for Veterinary Epidemiology and Econimics, Boxtel; 1993. p. 15

41. Woodbine KA, Medley GF, Moore SJ, Ramirez-Villaescusa AM, Mason S, Green LE. A four year longitudinal sero-epidemiological study of bovine herpesvirus type-1 (BHV-1) in adult cattle in 107 unvaccinated herds in south West England. BMC Vet Res. 2009;5:5,

42. McDermott JJ, Kadohira M, O'Callaghan CJ, Shoukri MM. A comparison of different models for assessing variations in the sero-prevalence of infectious bovine rhinotracheitis by farm, area and district in Kenya. Prev Vet Med. 1997;32:219-34.

43. Solis-Calderon JJS-CV, Segura-Correa JC, Alvarado-Islas A. Seroprevalence of and risk factors for infectious bovine rhinotracheitis in beef cattle herds of Yucatan. Mexico Prev Vet Med. 2003;57:199-208.

44. Speybroeck N, Boelaert F, Renard D, Burzykowski T, Mintiens K, Molenberghs G, Berkvens DL. Design-based analysis of surveys: a bovine herpesvirus 1 case study. Epid Infect. 2003:131:991-1002.

45. Van Wuijckhuise L, Bosch J, Franken P, Frankena K, Elbers AR. Epidemiological characteristics of bovine herpesvirus 1 infections determined by bulk milk testing of all Dutch dairy herds. Vet Record. 1998;142:181-4.

46. Raaperi K, Bougeard S, Aleksejev A, Orro T, Viltrop A. Association of herd BRSV and BHV-1 seroprevalence with respiratory disease and reproductive performance in adult dairy cattle. Acta Vet Scand. 2012;54:4.

47. Blacklaws BA, Berriatua E, Torsteinsdottir S, Watt NJ, de Andres D, Klein D, Harkiss GD. Transmission of small ruminant lentiviruses. Vet Microbiol. 2004; 101:199-208.

48. Leitner G, Krifucks O, Weisblit L, Lavi Y, Bernstein S, Merin U. The effect of caprine arthritis encephalitis virus infection on production in goats. Vet $\mathrm{J}$. 2010;183:328-31.

49. Patel JR, Heldens JG, Bakonyi T, Rusvai M. Important mammalian veterinary viral immuno diseases and their control. Vaccine. 2012;30:1767-81.
50. OIE. Manual of Diagnostic Tests and Vaccines for Terrestrial Animals. 2016. http://www.oie.int/en/international-standard-setting/terrestrial-manual/ access-online/. Accessed 27 Feb 2017.

51. Lee J, Tan CS, Chia KS. A practical guide for multivariate analysis of dichotomous outcomes. Ann Acad Med Singap. 2009;38:714-9.

52. Hill G. Model checking and comparison. In data analysis using regression and multilevel/hierarchical models. Cambridge University Press. 2007:513-27.

\section{Submit your next manuscript to BioMed Central and we will help you at every step:}

- We accept pre-submission inquiries

- Our selector tool helps you to find the most relevant journal

- We provide round the clock customer support

- Convenient online submission

- Thorough peer review

- Inclusion in PubMed and all major indexing services

- Maximum visibility for your research

Submit your manuscript at www.biomedcentral.com/submit
Biomed Central 